\title{
A HISTÓRIA NOVA DO BRASIL ENQUANTO LUGAR DE MEMÓRIA E LIVRO DIDÁTICO E POLÍTICO
}

\author{
THE HISTÓRIA NOVA DO BRASIL AS A PLACE OF MEMORY AND DIDACTIC \\ AND POLITICAL TEXTBOOK
}

Tiago Conte ${ }^{1}$

\begin{abstract}
RESUMO: Lançada às vésperas do golpe de 1964, a História Nova do Brasil foi uma coleção de livros didáticos destinada aos professores secundários de história. Elaborada no Instituto Superior de Estudos Brasileiros (ISEB) por encomenda do Ministério da Educação e Cultura (MEC), a coleção foi um dos primeiros alvos da repressão que se seguiu com o golpe, tendo seus volumes apreendidos e seus autores presos. Contudo, embora suas edições e vínculos institucionais tenham sido indicados em outros trabalhos, a História Nova do Brasil ainda está por ser analisada por outros aspectos. Este artigo pretende avaliar a coleção enquanto lugar de memória, segundo o conceito de Pierre Nora, e em suas dimensões políticas e cognitivas, conforme as teorias de Jörn Rüsen sobre cultura história e consciência histórica.
\end{abstract}

Palavras-chave: História Nova do Brasil. Lugares de memória. Dimensões políticas e cognitivas da história.

\begin{abstract}
Released on the eve of the 1964 coup, the História Nova do Brasil was a collection of textbooks for history teachers of secondary education. Elaborated in the Instituto Superior de Estudos Brasileiros (ISEB) by order of the Ministry of Education and Culture (MEC), the collection was one of the first targets of repression that followed the coup, having is volumes seized and the authors, imprisoned. However, although the História Nova do Brasil editions and institutional links have been indicated in other works, it stills has to be analyzed in other aspects. This article intends to evaluate the collection as a place of memory, in accordance to Pierre Nora's concept, and in your political and cognitive dimensions, in according to Jörn Rüsen's theories about historical culture and historical conscience.
\end{abstract}

Keywords: História Nova do Brasil. Places of memory. Political and cognitive dimensions of history.

\footnotetext{
${ }^{1}$ Mestre em História pela Universidade do Vale do Rio dos Sinos (UNISINOS), doutorando em História pela Pontifícia Universidade Católica do Rio Grande do Sul (PUCRS). Bolsista Capes/PROSUC.
} 


\section{Introdução}

Objeto de polêmicas, desde sua elaboração até seu lançamento, a História Nova do Brasil já foi analisada, quanto a seu contexto de produção e trajetória editorial, em outros trabalhos. Sem esgotar o assunto, a literatura produzida, até o momento, aponta para aspectos passíveis de novas pesquisas, especialmente as influências das diferentes instituições que fomentaram a realização do projeto. No entanto, dentro dos limites de um artigo, pretendo apontar para outra abordagem a respeito, com base nas considerações de Pierre Nora, quanto aos lugares de memória, e as elaborações teóricas de Jörn Rüsen, quanto às dimensões políticas e cognitivas da História. Antes de passar a essas análises, contudo, se faz necessário um breve levantamento sobre a origem e o percurso da História Nova do Brasil, em suas diferentes edições, pois a perseguição movida contra a obra fez com que ela se tornasse um lugar de memória, posteriormente.

Entre 1963 e 1964, um grupo de historiadores, reunidos no Instituto Superior de Estudos Brasileiros (ISEB), elaborou uma coleção de textos didáticos que visava apresentar a História do Brasil com uma abordagem diferente das que eram ensinadas na época. Inicialmente, destinados aos professores do ensino secundário, esses livros pretendiam servir de complemento ao material didático de então. A novidade que os autores pretendiam apresentar estava expressa, inclusive, no título da obra: História Nova do Brasil (doravante HNB). Composta e lançada em pleno governo de João Goulart, a HNB oferecia uma História declaradamente nacionalista e militante, o que acabou por influenciar em sua recepção e trajetória posterior. Projetada, inicialmente, para dez volumes, cinco haviam sido publicados até o golpe de 1964, quando a coleção foi apreendida e seus autores foram presos. Nesse aspecto, "Nunca, na História do Brasil, um projeto ou confecção de livros didáticos para o ensino médio provocara tanto terror e represálias a seus autores" (PINTO, 2006, p. 343), o que levou alguns de seus autores a se exilarem. 
Numa primeira leitura, além dos significados políticos do projeto, ao menos dois aspectos da HNB se sobressaem: a elaboração coletiva do trabalho e a postura crítica em relação à História ensinada na época. 0 trabalho conjunto foi realizado em relação a cada um dos textos, conforme o depoimento de Nelson Werneck Sodré:

\begin{abstract}
Havia um relator, escolhido por todos e variável, que elaborava um texto preparatório. Cada um estudava esse texto e anotava, segundo as pesquisas que fizera enquanto o relator elaborava parceladamente o texto básico. Depois, reuniam-se todos, em sessões seguidas, discutiam o texto proposto e as alterações que cada um apresentava [...]. Só então, e depois de intensa discussão, era elaborado o texto definitivo (SANTOS et al., 1993, p.33).
\end{abstract}

Esse processo de escrita, leitura e discussão coletiva em relação a cada parte da HNB, fazia com que o trabalho passasse por uma avaliação crítica desde o princípio, assim como evitava que a coleção fosse obra de um responsável principal em detrimento dos demais. Sabe-se que a autoria da HNB foi atribuída, principalmente, a Nelson Werneck Sodré, o historiador mais reconhecido no grupo, embora o próprio Sodré ressaltasse o caráter coletivo do trabalho ${ }^{2}$. Os outros participantes eram egressos da Faculdade Nacional de Filosofia (FNFi) do Rio de Janeiro, a saber: Joel Rufino dos Santos, Maurício Martins de Mello, Pedro de Alcântara Figueira, Pedro Celso Uchôa Cavalcanti, Rubem César Fernandes e Francisco Falcon ${ }^{3}$. Contudo, apesar de seis dos sete responsáveis pela HNB serem formados na FNFi, a coleção foi elaborada no ISEB, onde Sodré ministrava aulas de História do Brasil $^{4}$. Essa diferença, entre o local de formação acadêmica e o lugar onde a HNB foi composta, remete a uma trama de diferentes instituições às quais

${ }^{2}$ Em outro depoimento, Pedro Celso Uchôa Cavalcanti Neto afirma que Sodré não queira que os demais autores fossem seu "papel carbono", meros reprodutores de suas ideias (SANTOS et al., 1993, p. 59). Contudo, avaliar a influência de Sodré na escrita da HNB ainda é uma questão a ser analisada com mais detalhes.

3 Cabe destacar que o nome de Francisco Falcon não consta na relação publicada de autores da HNB, embora ele tenha participado da elaboração do primeiro volume da série. Sobre a participação de Falcon, ver Pinto (2006, p. 354) e Santos et al. (1993, p. 53).

4 Sobre a formação acadêmica dos autores e a importância do ambiente da FNFi para a elaboração da HNB, a dissertação de Daniel Mesquita Pereira (1998) traz indicações importantes. Ao analisar a revista acadêmica publicada na faculdade entre 1958 e 1963, chamada Boletim de História, o autor identifica muitos dos projetos e disputas acadêmicas que constam mais tarde na HNB. Sodré ministrava o curso de Formação Histórica do Brasil no ISEB, além de ter chefiado o Departamento de História do Instituto. Sobre seus cargos no ISEB, ver Sodré (1987, p. 119). 
a HNB esteve relacionada, tanto por proximidade quanto por contraposição. Embora fuja dos limites deste artigo, o levantamento dessas relações é outro caminho de interpretação da obra passível de ser explorado.

Quanto às críticas ao material didático utilizado na época, elas não se reduzem a uma expressão pessoal dos autores. Afinal, uma História que se pretendia "nova" era feita em contraste com a História do Brasil ensinada até então. E, em vez de deixar tal posição implícita, as críticas, no plano do ensino e da escrita da História, eram declaradas já na introdução geral do trabalho:

Os livros didáticos de História são comprovadamente inadequados, pois neles o passado nada tem a ver com o presente, o Brasil pouquíssimas vezes tem a ver com o mundo, o enfoque meramente político impede o arrolamento de camadas e ações decisivas do nosso povo (SANTOS et al., 1965 , p. 13).

Essa diferença entre uma História do Brasil "velha", muitas vezes baseada em grandes personagens, e outra com foco no povo, também remete ao momento no qual a HNB foi composta e publicada, em pleno governo Goulart. Sabe-se que a principal bandeira do governo Jango eram as chamadas "reformas de base", as quais iam desde a reforma agrária e política até o sistema de ensino, onde o projeto da HNB se inseria: "Os ventos reformistas sopravam em todas as direções [...] O momento, portanto, também se mostrava oportuno para ensaiar uma reforma no ensino da história pátria" (GUIMARÃES; LEONZO, 2003, p. 236-237). No caso específico da História, tratava-se de apontar as insuficiências e alternativas para um ensino de acordo com a situação do país:

\footnotetext{
Portanto, não bastava questionar e demonstrar a péssima qualidade dos livros didáticos; algo teria de ser oferecido como alternativa ao retrógado. [...] Produzir um material didático alternativo à historiografia oficial - que resumia a História do Brasil a um amontoado de heróis e datas, sem qualquer questionamento das causas fundamentais dos fatos históricos - passou a ser a tarefa central do grupo, ou seja, elaborar uma nova análise da História do Brasil (MENDONÇA, 2006, p. 337-338).
}

Nesse contexto, a HNB fazia parte da agenda reformista do governo, de onde veio o impulso para sua elaboração. Produzida através de um 
convênio entre o ISEB e a Campanha de Assistência ao Estudante (Cases), órgão vinculado ao Ministério da Educação e Cultura (MEC), a HNB poderia ser distribuída a professores de todo o país. Contudo, ao mesmo tempo em que esse vínculo garantiu que a coleção chegasse a um público mais amplo, também causou reações negativas, especialmente a partir da imprensa. Em editoriais de O Globo, do Jornal do Brasil e do Estado de S. Paulo criticavase o "dirigismo pedagógico do governo", que estaria buscando impor um ensino doutrinário de História do Brasil em favor de seus projetos políticos (GUIMARÃES; LEONZO, 2003, p. 246; PINTO, 2006, p. 344). A repercussão causada por uma obra composta no ISEB, sob a supervisão de Nelson Werneck Sodré, figura reconhecidamente ligada às esquerdas do período ${ }^{5}$, conferiram a HNB uma dimensão política que muitas vezes deixou as questões históricas do trabalho em segundo plano ${ }^{6}$.

No cenário de polarização política em que foi publicada, a HNB foi dos primeiros alvos atingidos quando o golpe militar de 1964 eclodiu. Além da apreensão dos fascículos até então publicados, seus autores foram presos na onda de repressão que se seguiu após a derrubada do governo Jango. No entanto, a censura não se limitou ao confisco dos livros pelos militares, estendendo-se também a um parecer negativo sobre a obra publicado na revista do Instituto Histórico e Geográfico Brasileiro (IHGB). Encabeçada por

\footnotetext{
${ }^{5}$ Os intelectuais do ISEB organizavam cursos, conferências e escreviam sobre as questões políticas do momento em livros destinados ao grande público, defendendo pautas reformistas e nacionalistas ligadas às esquerdas do período (LOURENÇO, 2008, p. 390391). No caso de Sodré, sabe-se que ele era membro do Comitê Cultural do Partido Comunista Brasileiro (PCB), órgão que influenciou a composição dos departamentos culturais do ISEB, a partir de 1961 (CZAJKA, 2009, p. 112).

6 Sobre a repercussão em torno da HNB e sua possível utilização em sala de aula, o artigo de João Luis da Silva Bertolini (2014) trata do decreto 53.583/64, que determinava a inclusão dos livros editados pelo MEC entre o material passível de ser selecionado nas escolas. Desse modo, o uso da HNB não era obrigatório, mas o livro deveria constar na biblioteca das escolas públicas e particulares. Em outro artigo, Adriano Nervo Codato e Marcus Roberto de Oliveira (2004) tratam de uma passeata realizada em Curitiba, no dia 24 de março de 1964, batizada "Marcha a favor do ensino livre". Reunindo entre quatro e trinta mil pessoas, conforme estimativas da época, a passeata se insurgia contra a adoção do "Livro único" do MEC nas escolas. É interessante observar que, nos depoimentos de organizadores do protesto, em nenhum momento é mencionado o nome do livro contra o qual a passeata foi organizada. Chamado apenas de "Livro único", diz-se que ele "foi escrito pelo historiador Nelson Werneck Sodré possivelmente a partir de seus cursos no Instituto Superior de Estudos Brasileiros e recontava o processo de organização da sociedade brasileira contrariando os principais mitos da História tradicional. Além disso, consta que a brochura fazia apologia do programa das 'Reformas de Base'" (CODATO; OLIVEIRA, 2004, p. 287). Parecem indícios de que a HNB foi interpretada, principalmente, pela participação de Sodré no projeto e pela conjuntura política da época, acima de considerações quanto aos aspectos historiográficos da obra.
} 
Américo Jacobina Lacombe, a comissão do instituto encarregada de avaliar a HNB acusou uma série de distorções no tratamento da história do Brasil, desqualificando seus autores enquanto historiadores: "Ora defendem os AA suas teses com parcialismo flagrante na interpretação de fatos, ora cometem enganos e deturpações imperdoáveis, máxime da parte de quem se propõe a corrigir e emendar mestres consagrados" (LACOMBE et al., 1964, p. 285). Além disso, a HNB foi criticada por excluir qualquer influência sobre a história além de fatores econômicos, sendo caracterizada como obra de propaganda ideológica marxista. Deste modo, os pareceristas recomendavam o cancelamento do projeto e de sua veiculação pelo MEC.

Mas a trajetória da HNB não foi encerrada em definitivo a partir disso. Uma segunda edição, publicada pela editora Brasiliense em 1965, agrupou sete das dez monografias originais em dois volumes, num projeto que pretendia chegar a seis livros ${ }^{7}$. Desses, foram lançados os volumes um e quatro, mas a edição foi apreendida logo após o lançamento. Num procedimento incomum para um conjunto de livros, a segunda edição da HNB foi submetida a um Inquérito Policial-Militar (IPM) específico:

Enquanto nos "inquéritos institucionais", a exemplo do IPM do PCB, IPM do ISEB, IPM do MEC, a denúncia é formulada a partir do crime cometido por uma organização ou entidade, neste IPM da História Nova, o crime de subversão é especificado na ação de cada um dos denunciados (CZAJKA, 2009, p. 195).

Desse modo, não apenas os autores como também os livreiros que vendiam a coleção em suas lojas, passaram a ser alvos de investigação por veicularem material considerado subversivo. Em resposta a essa série de perseguições, Nelson Werneck Sodré escreveu dois textos, publicados pela Revista Civilização Brasileira, nas edições de julho e setembro de 1965. Neles, destacou as arbitrariedades das quais os autores foram vítimas e rebateu o parecer negativo publicado pelo IHGB, especialmente Lacombe. Entre os argumentos, Sodré ressalta a contradição existente entre a

\footnotetext{
7 Em depoimento alusivo aos trinta anos da série, Pedro Celso Uchôa Cavalcanti Neto afirma que o projeto original havia sido ampliado para dezesseis monografias até a eclosão do golpe de 1964, "em virtude do grande sucesso inicial" (SANTOS et al., 1993, p. 63).
} 
desqualificação da HNB e a dimensão política da qual ela foi revestida pelas autoridades:

É preciso considerar, antes de tudo, que a História Nova do
Brasil é talvez a obra científica que, em todos os tempos, foi
mais acusada de inferior e, entretanto, mais mereceu
"pareceres". Sobre essa coisa desimportante, errada,
desqualificada, manifestaram-se, em "pareceres", o Estado
Maior do Exército, o Instituto Histórico e Geográfico
Brasileiro, a Comissão Nacional do Livro Didático, etc. É
muita força para tanta fraqueza (SODRÉ, 1987, p. 142).

Uma terceira edição, publicada em 1993 para marcar os trinta anos de lançamento da edição original, reúne depoimentos da maioria dos autores e o primeiro dos fascículos originais, "O Descobrimento do Brasil". Neste breve resumo do trajeto editorial da HNB, nota-se que a coleção foi alvo de críticas e polêmicas, que muitas vezes extrapolaram as salas de aula. Além da dimensão política do momento, seu lançamento ocasionou um embate entre instituições e conceitos de história diferentes, quando não opostos.

No entanto, apesar da repercussão e dos debates que suscitou na época de seu lançamento, este trabalho pretende abordar a HNB por outros aspectos. A trajetória editorial da coleção, seus vínculos institucionais, suas fontes e os conceitos utilizados para elaborar uma nova História do Brasil, em contraste com um modelo vigente ensinado nas escolas, são aspectos da HNB passíveis de serem avaliados em trabalhos mais extensos. Dentro dos limites deste texto, porém, pretendo seguir duas sugestões apontadas por outros autores com base em autores específicos: a HNB como lugar de memória e as dimensões política e cognitiva da coleção.

\section{Dimensão política e lugar de memória}

Em artigo sobre a HNB, Lucia Guimarães e Nanci Leonzo (2003) mencionam a edição de 1993 como exemplo de lugar de memória, tomando o conceito formulado por Pierre Nora. Contudo, as autoras não especificam o que insere essa edição na categoria. Trata-se de uma leitura da HNB pouco explorada até o momento, por onde este trabalho pretende apresentar algumas indicações e possibilidades de interpretação. De 
maneira semelhante, os conceitos formulados por Jörn Rüsen, quanto às dimensões política e cognitiva da História, sugerem uma outra de interpretação da HNB, um caminho a ser indicado sem ser percorrido por completo, dados os limites de um artigo.

Sobre o conceito de "lugar de memória", vale ressaltar a distinção que Nora faz entre memória e História, um processo que as tornou cada vez mais apartadas ao longo do tempo. Partindo do contexto francês, o autor identifica no desaparecimento do campesinato, na crise das ideologias que explicavam a passagem do passado ao futuro e na crise das histórias de tipo nacional, três fatores que afastaram História e memória. Em comum, essas mudanças significam um rompimento entre passado e presente, vistos agora como descontínuos entre si. Além disso, enfraqueceram-se, também, as identidades que davam suporte às memórias coletivas, fossem de camponeses ou identidades nacionais. Na disciplina histórica, esse distanciamento entre memória e História resulta numa História da História, em reflexões sobre os procedimentos da disciplina e de sua difusão: "O nascimento de uma preocupação historiográfica, é a história que se empenha em emboscar em si mesma o que não é ela própria, descobrindose como vítima da memória e fazendo um esforço para se livrar dela" (NORA, 1993, p. 10). História, nação e memória não são mais tomadas como sinônimos, assim como as histórias baseadas numa perspectiva nacional não abarcam mais a "consciência da coletividade".

Diante dessas mudanças, a História passa a trabalhar como uma espécie de substituta da memória. É nesse contexto que surgem os lugares de memória que, segundo o autor, são "restos" das antigas formas de identificação coletiva entre passado e presente. Cresce a consciência do trabalho histórico propriamente dito, dos procedimentos que tornam parte do passado História:

Os lugares de memória nascem e vivem do sentimento que não há memória espontânea, que é preciso criar arquivos, que é preciso manter aniversários, organizar celebrações, pronunciar elogios fúnebres, notariar atas, porque essas operações não são naturais (NORA, 1993, p. 13). 
Segundo Nora (1993), essa dimensão deliberada distingue a "memória verdadeira" daquela transformada em História. Baseada em arquivos cada vez maiores, a memória histórica corre o risco de se tornar ininteligível pelo excesso, ao mesmo tempo em que cada indivíduo se torna "historiador de si mesmo". De prática social, a memória passa a ser uma obrigação individual, no que o autor chama de "terrorismo da memória historicizada" (NORA, 1993, p. 17). Multiplicaram-se os apelos à memória justamente por se perceber que ela está desaparecendo, mas o que constitui os lugares de memória?

De acordo com o autor, uma condição inicial para a formação de lugares de memória é haver uma "vontade de memória" sobre o objeto em questão. Do contrário, "[...] derivar-se-ia de uma definição estreita, a mais rica em potencialidades, para uma definição possível, mais maleável, susceptível de admitir na categoria todo objeto digno de uma lembrança" (NORA, 1993, p. 22). No caso da HNB, publicada em 1993, o lançamento marcado para trinta anos depois da edição original e os depoimentos dos autores, atestam essa deliberação de memória. Contudo, a dimensão voluntária não esgota a definição do conceito, e Nora salienta que o lugar de memória não se limita a um local físico. Há, pelo menos, três sentidos para "lugar", sendo que todos estão presentes nos lugares de memória, em graus diferentes. São lugares, tanto no aspecto material quanto no funcional e no simbólico, o que faz com que o conceito abarque objetos diferentes entre si:

Mesmo um lugar de aparência puramente material, como um depósito de arquivos, só é lugar de memória se a imaginação o investe de uma aura simbólica. Mesmo um lugar puramente funcional, como um manual de aula [...] só entra na categoria se for objeto de um ritual. Mesmo um minuto de silêncio [...] é ao mesmo tempo o recorte material de uma unidade temporal e serve, periodicamente, para uma chamada concentrada da lembrança (NORA, 1993, p. 21-22).

Assim, os lugares de memória não se reduzem a monumentos ou construções, como poderia parecer ao senso comum de "lugar". A HNB, de 1993, parece conter esses significados, a começar pelo fato de que a reedição pela editoria Giordano fazia parte de uma Coleção Memória. Além 
disso, na apresentação ao livro o editor afirma o propósito da obra, que não se resumia a republicar os textos ou avaliar sua qualidade enquanto historiografia:

[...] porquanto sua preocupação não foi nem é a de reafirmar a validade ou verdade dos textos da $\mathrm{HNdB}$, e sim reavivar um episódio da nossa história, que lhe parece sintomático e da maior relevância para explicar por que somos um país de desmemoriados, por que não nos personalizamos historicamente (SANTOS et al., 1993, p. 11).

À dimensão material do livro e à dimensão funcional de ser um material didático, mesmo que de outra época, soma-se a dimensão simbólica da HNB como projeto que procurou repensar a historiografia brasileira de nível didático. Ao mesmo tempo, a reedição da obra contrasta com o silêncio no qual ficou por trinta anos, num movimento entre memória e esquecimento, que Nora também avalia. Um exemplo, nesse sentido, é o Tour de la France par deux enfants, livro didático para crianças, lançado em 1877, e que alcançou sucessivas reedições até as vésperas da Primeira Guerra, quando deixa de ser editado e passa da memória coletiva para a memória histórica e pedagógica. Cem anos depois, porém, o livro é reimpresso e "[...] entra novamente na memória coletiva, não a mesma, enquanto espera novos esquecimentos e novas reencarnações" (NORA, 1993 , p. 23). Dessa forma, percebe-se que os lugares de memória podem perder e readquirir esse status com o tempo, conforme os interesses de leitores e pesquisadores em cada época.

As reflexões de Nora também se estendem aos livros de História, dado que eles são os instrumentos delimitadores dos limites entre memória e História. No entanto, o autor destaca que a maioria deles não são lugares de memória, nem mesmo os que trabalhavam num regime histórico anterior que aproximava as duas instâncias: "Entre os livros de história são unicamente lugares de memória aqueles que se fundam num remanejamento efetivo da memória ou que constituem os breviários pedagógicos" (NORA, 1993, p. 24). São poucos os exemplos nesse sentido, porque se tratam de trabalhos que fixam uma nova memória histórica, novos paradigmas para o conhecimento histórico. Considerando que a HNB se destinava aos professores do ensino secundário, o que the confere um 
caráter pedagógico, seria a coleção um lugar de memória enquanto livro de História?

No artigo que dedicam à HNB, Guimarães e Leonzo (2003) ressaltam o quanto a coleção estava inserida no contexto político do governo Goulart, quando as principais discussões giravam em torno das reformas de base. $O$ governo e os grupos que o apoiavam defendiam reformas capazes de transformar as chamadas "estruturas arcaicas" da sociedade brasileira em diversos campos: reforma agrária, universitária, eleitoral, etc. Sabe-se que a HNB foi elaborada no Instituto Superior de Estudos Brasileiros (ISEB), centro de estudos e de produção teórica com posições nacionalistas e favorável ao governo Jango. Neste cenário, a HNB seria um projeto de reforma no ensino da História do Brasil (GUIMARÃES; LEONZO, 2003, p. 237). Produzida por encomenda de um órgão do Ministério da Educação e Cultura (MEC), a coleção pretendia abarcar do período das grandes navegações até os anos mais recentes.

Contudo, com o golpe de 1964 a coleção foi apreendida e o projeto cancelado quando haviam sido lançados cinco dos dez volumes previstos inicialmente. Por ser distribuída pelo ministério, a HNB foi submetida a um parecer do Instituto Histórico e Geográfico Brasileiro (IHGB). Nesse parecer, a HNB foi desqualificada como tentativa de aplicar conceitos marxistas na análise da história do Brasil:

Mais materialistas que Marx, os nossos dialetas-historiadores
vão às extremas da interpretação dialética e varrem da
História do Brasil a influência de qualquer personalidade,
qualquer corrente, qualquer fator que não seja
exclusivamente mercantil (LACOMBE et al., 1964, p. 291).

Guimarães e Leonzo (2003) mencionam o quanto o IHGB esteve ligado a um determinado projeto político, apresentando a História do Brasil como ausente de conflitos. Retomando os conceitos de Nora, seria um exemplo de História-memória, em que Estado e nação eram apresentados como indivisíveis. Contra esse modelo, a HNB propunha um alargamento vertical e horizontal no estudo da História: vertical no estudo sobre as classes populares, sem se deter apenas nas "grandes figuras" das elites, e horizontal ao relacionar a História do Brasil com o contexto mundial. No 
entanto, também a HNB continha um projeto político em sua concepção, como se depreende da introdução geral da obra:

Em nossa opinião, a História não é uma diversão; sua função social está justamente no fato de que the cabe explicar o presente. Mostrar o nexo passado-presente, sobretudo em nosso país onde muita coisa estacionou, não só é necessário, como a única forma de estudar História (SANTOS et al., 1993, p. 121).

No combate às "estruturas arcaicas", a História assumia uma posição declaradamente militante. Tal perspectiva, ainda que se contrapusesse aos livros de História produzidos então, não era menos pragmática do que as posições anteriores. Pois, se antes o passado - ou um remanejo do passado - conferia legitimidade ao Estado, como nas produções do IHGB, na HNB o conhecimento se ligava às demandas sociais e políticas do momento em que foi produzida. Buscava-se reformular o passado, a partir de uma perspectiva brasileira e nacionalista:
A historiografia deveria cumprir a missão de, ao proporcionar a inteligibilidade do presente, revelar os entraves à continuidade do desenvolvimento brasileiro. Nesta perspectiva, o historiador autêntico seria aquele que diria em que ponto da evolução do processo histórico se situam as forças sociais, diagnóstico necessário para que se oriente aquele numa direção desejada (PEREIRA, 1998, p. 85) ${ }^{8}$.

Ao avaliarem o parecer do IHGB sobre a HNB, Guimarães e Leonzo (2003, p. 246) falam num "duelo entre duas histórias oficiais", porque ambas continham concepções de História e projetos políticos opostos entre si. Voltando às reflexões de Nora, a coleção procurou ser um remanejamento da memória e breviário pedagógico, capaz de fixar uma nova memória histórica do Brasil. Seu cancelamento e as apreensões dos livros posteriores impediram que a HNB se tornasse um lugar de memória

\footnotetext{
8 "Autenticidade", "alienação" e "desenvolvimento brasileiro" eram conceitos comuns às produções do ISEB, onde a HNB foi composta. Um trabalho fundamental para a compreensão do ISEB é o de Caio Navarro de Toledo (1977). Ao mesmo tempo, a maioria dos autores da HNB vinham da Faculdade Nacional de Filosofia (FNFi) do Rio de Janeiro, e as demandas dos estudantes quanto ao ensino de história também tiveram reflexos na HNB. Neste sentido, o artigo de João Alberto da Costa Pinto (2006) e a dissertação de Daniel Mesquita Pereira (1998) indicam as relações da coleção com as pautas discentes naquele contexto.
} 
na historiografia, o que a edição de 1993 procurou fazer três décadas depois.

Além dos esforços para se instituir em lugar de memória e dos fundamentos teóricos da coleção, apenas esboçados, outro aspecto relevante da HNB está na proposta didática do projeto. Afinal, o livro didático contém uma série de demandas: de pais e alunos, que esperam informações sobre o passado, o que também deve ser ensinado pelo professor; e do Estado, que monta currículos e promove a produção de materiais, de acordo com suas diretrizes oficiais (BERTOLINI, 2014, p. 95). Essas demandas fazem com que os livros didáticos e o aprendizado histórico apresentem uma dimensão cognitiva e também uma dimensão política. Nesse sentido, as reflexões de Jörn Rüsen e Friedrich Jaegger sobre o pensamento histórico são especialmente relevantes.

Os autores alemães não ignoram o conceito de "lugares de memória" formulado por Nora, ressaltando sua importância para o surgimento de novas pesquisas sobre museus, arquivos e exposições, por exemplo. Novos temas e métodos de pesquisa, dedicados à formação desses lugares, surgiram com o uso dessa categoria, de maneira mais crítica e reflexiva. No entanto, Rüsen e Jaegger criticam a existência de um ponto fraco no conceito, o "de privilegiar unilateralmente o complexo dos aspectos simbólicos, estéticos e afetivos da cultura da memoração e tender a desviar o foco da dimensão didática, científica e política da cultura da memoração ou então a negligenciá-la" (RÜSEN; JAEGGER, 2014, p. 120). Sem menosprezar a importância dos aspectos mais simbólicos, os autores argumentam que as formas científicas da História também fazem parte dessa cultura da memoração, sem necessariamente anularem os primeiros.

Para descrever as relações entre as formas científicas e não científicas de História, os autores apresentam uma tipologia detalhada. Num primeiro plano, Rüsen e Jaegger levantam a categoria de cultura histórica, que é por onde se forma a consciência histórica de um grupo ou sociedade. Essa formação se dá num âmbito heterogêneo da vida cultural, em atividades e produções, dentro e fora das salas de aula. A consciência histórica atua como um tipo complexo de memoração, pois remete a acontecimentos e 
períodos que ultrapassam o tempo de vida dos indivíduos. No entanto, os autores destacam que isso não abrange todo o passado, pois a consciência histórica possui uma função orientadora:

\begin{abstract}
Nem todo ato de narrar é histórico; só quando atualiza a experiência do que aconteceu no passado de modo a situá-la numa conexão temporal significativa e relevante com o presente é que ele passa a sê-lo e exerce a função específica da orientação temporal mediante a experiência interpretada do passado (RÜSEN; JAEGGER, 2014, p. 98).
\end{abstract}

As conexões entre passado e presente também fazem referência ao futuro, a um horizonte de experiência e de expectativa pelo qual o tempo adquire sentido histórico. A formação histórica de sentido, por sua vez, "integra experiências, interpretações, orientações e motivações que se referem a experiências do passado como condições para a compreensão do presente e para a expectativa do futuro, numa estrutura coerente de sentido, numa 'história'" (RÜSEN; JAEGGER, 2014, p. 101). Todos esses processos acontecem dentro de uma cultura histórica, que os autores consideram a quinta-essência das atividades e instituições pelas quais a consciência histórica acontece.

Dentro da categoria de cultura histórica, Rüsen e Jaegger diferenciam três dimensões elementares: a estética, a cognitiva e a política. A dimensão estética refere-se à capacidade persuasiva e de congruência formal e performativa. Os meios de comunicação em massa, as produções artísticas, os museus e exposições são exemplos de formação histórica de sentido pela estética, utilizando-se de formas da imaginação para conferir um feitio à consciência histórica. A dimensão cognitiva trata das pretensões de validade através da argumentação, plano onde a ciência histórica atua. A racionalidade metódica e o uso de regras de pesquisa conferem credibilidade ao que é produzido no âmbito cognitivo da História, como nos livros didáticos, por exemplo.

Por sua vez, a dimensão política se refere a questões de legitimidade enquanto fator de poder. Esse aspecto da cultura histórica é importante para todos os governos, pois "Nenhum sistema de dominação pode renunciar à cultura histórica enquanto instância de legitimação, e a crítica da legitimação sempre recorre também à argumentação histórica" (RÜSEN; 
JAEGGER, 2014, p. 102). Os autores salientam que essas dimensões não se reduzem uma à outra, mas em relações complexas que variam em grau. No caso da HNB, havia um componente cognitivo e político no projeto, assim como nas críticas dirigidas a ele. A formação histórica de sentido buscava outros fatores, longe dos "grandes homens" do passado, e outros projetos de futuro, próximos ao que Daniel Pereira (1998) apontou na busca por uma História do Brasil "autêntica".

Em avaliações posteriores sobre a HNB, alguns de seus autores reconheceram a relação entre as dimensões cognitiva e política da obra. Sem mencionar Rüsen e Jaegger, o depoimento de um deles coincide com as questões levantadas pelos autores alemães, sobretudo na visão da História como legitimidade de um poder. Diante da perseguição a que os livros e seus autores foram submetidos, após o golpe de 1964,

Só então comecei a compreender verdadeiramente, em todas as suas dimensões, e não apenas como conhecimento teórico, a importância da História para a vida dos povos e para o poder. [...] Ter uma visão da História, fazê-la $A$ Verdade histórica - é necessário para se ocupar o poder. É instrumento vital para justificar o status quo, ou em que direção se deve caminhar. Seus símbolos podem servir à ditadura, criar nacionalismos, exaltar democracias (SANTOS et al., 1993, p. 63).

O que poderia fazer da História um simples instrumento do poder é contrabalançado pela argumentação de Rüsen de que "As pretensões de legitimação política perdem credibilidade e poder de convencimento quando incompatíveis com a verdade científica" (BERTOLINI, 2014, p. 103). O parecer negativo do IHGB, por exemplo, desqualificou a HNB como obra que distorcia a História do Brasil numa interpretação estritamente marxista. Contudo, seus autores afirmavam que a obra não apresentava novas teses, mas que ela "por um lado, assenta em teses predominantes na historiografia contemporânea; por outro, no que se refere propriamente à nossa História, em autores de nomeada" (SANTOS et al., 1993, p. 121). Os críticos da HNB a desqualificaram como obra de cunho meramente político; aqueles que a defenderam tomaram a coleção como uma reforma do ensino de história praticado até então no país. Contudo, as argumentações de Rüsen apontam que as dimensões políticas e cognitivas no livro didático são 
indissociáveis, o que não impede que se faça uma análise dos métodos utilizados na sua elaboração.

No campo didático, vale destacar que os autores da HNB tinham por principal objetivo a reformulação dos conteúdos, mais do que novas técnicas de ensino. Nesse sentido, o conceito de didática, presente na coleção, consiste em adaptar os conteúdos dos 'autores de nomeada' ao contexto escolar. Ao considerarem as possíveis formas de ensino de História a serem utilizadas em sala de aula, os autores esclarecem que elas seriam válidas na medida em que levassem à compreensão do conhecimento histórico:

\begin{abstract}
Julgamos que são perfeitamente válidas desde que pressuponham um conhecimento adequado do assunto pelo professor e levem os alunos, por diferentes caminhos, a compreendê-lo. Afirmamos, sim, que sem uma visão justa e integral do problema, dentro de uma fundamentação conceitual precisa, toda e qualquer técnica será inútil porque estará destituída daquilo que é a sua própria razão de ser, o conhecimento histórico como tal, sem adjetivos nem preconceitos (SANTOS et al., 1965, p. 7).
\end{abstract}

Nesse sentido, a didática seria uma forma de transmissão do conhecimento histórico do professor para os alunos, desconsiderando outras formas de elaboração da História e mesmo da escola, como produtora de conhecimento histórico. Trata-se de uma perspectiva anterior a de autores mais recentes, que trazem conceitos como "cultura escolar" e "Didática da História" para analisar as formas de elaboração da História além dos meios acadêmicos, da "História dos historiadores". Por essa nova abordagem, as relações entre didática e História são avaliadas em relação à Teoria da História, abrindo caminho para novas interpretações (CARDOSO, 2008) ${ }^{9}$.

No entanto, o enfoque no conteúdo das monografias não se deu apenas a partir dos autores da HNB. Ao comentar a intensa campanha contra a coleção movida por jornais e outras entidades da época, que a criticaram como obra de doutrinação ideológica para a juventude, Vanessa Cardoso aponta para a concepção de ensino implícita nessas avaliações:

\footnotetext{
9 Rüsen é um exemplo de autor que analisa as relações entre diferentes formas de cultura e consciência histórica, tanto as produzidas nas universidades e salas de aula quanto aquelas elaboradas de forma não científica, como em filmes, peças de teatro, livros de ficção entre outras.
} 
É importante ressaltar que ao criticar o conteúdo da obra didática [...] concebe-se o uso do livro em sala de aula excluindo a responsabilidade do professor em instruir o seu uso, concebe-se também o leitor do livro como sujeito passivo, e o seu uso como uma prática de mão única. Desconsidera-se o fato de o leitor ter liberdade para fazer a sua leitura do livro e o seu uso em sala de aula ser de responsabilidade do professor (CARDOSO, 2016, p.145).

Dessa maneira, sem ignorar sua dimensão cognitiva, é possível afirmar que a recepção da HNB se deu, especialmente, por sua dimensão política. No contexto de polarização em que a obra foi lançada, os possíveis efeitos da coleção no plano didático ficaram em segundo plano, se comparados às implicações políticas com que a obra foi investida. E, embora pretendesse representar uma reforma no Ensino de História do Brasil, a HNB foi tomada nesse aspecto inclusive por aqueles que a utilizaram:

A História Nova valeu menos pela aplicação - pois pouca gente aplicou - e mais pelo impacto por colocar a péssima qualidade dos livros didáticos da época e oferecer uma alternativa. [...] Foi bem recebida pelos militantes de esquerda: eu, por exemplo, que tinha militância política, quando peguei a História Nova achei uma beleza. Estava dentro do quadro das reformas de Goulart (MENDONÇA, 1990 , p. 35).

Elaborada como lugar de memória e como parte da cultura histórica do período, a HNB pretendeu apresentar a História do Brasil sob outra forma. Segundo seus autores, não se tratava de uma obra inédita no conteúdo, mas de uma reformulação daquilo que era ensinado nas salas de aula, uma História que não exaltava os "heróis" da nacionalidade. No entanto, por ter sido produzida no ISEB e, principalmente, pela participação de Nelson Werneck Sodré no projeto, a coleção foi lida como obra marxista ${ }^{10}$ e por isso foi apreendida após o golpe. A HNB ainda está por ser analisada em

\footnotetext{
${ }^{10}$ Trata-se de uma questão ainda em aberto. Nelson Werneck Sodré era notoriamente ligado ao Partido Comunista Brasileiro (PCB), e alguns dos demais autores da coleção também eram membros do partido na época, como Pedro Celso Uchoa e Joel Rufino dos Santos. Em entrevista, Pedro Celso confirmou a importância fundamental de Sodré para o projeto, embora ele não reconhecesse a HNB como portadora de uma concepção marxista de História. Além disso, a elaboração coletiva dos livros fez com que a coleção apresentasse diferenças em relação aos trabalhos de Sodré (FERREIRA, 2013, p. 380-381). Em depoimento alusivo aos trinta anos da série, Pedro de Alcântara Figueira criticou a HNB como uma tentativa equivocada de conciliar marxismo e nacionalismo, perspectivas que seriam incompatíveis entre si (SANTOS et al., 1993, p. 38).
} 
mais detalhes enquanto obra historiográfica, mas pode-se contatar que a coleção procurou fixar uma nova memória histórica no país em um nível didático, ao alcance de um público muito mais amplo do que nas academias. O que deu à HNB uma repercussão maior do que seus autores imaginavam, especialmente com a perseguição que se seguiu.

\section{Referências}

BERTOLINI, João Luis da Silva. Passeata contra o livro de História único: Curitiba, 24 de março de 1964. In: ABUD, Kátia; SCHMIDT, Maria Auxiliadora (org.). 50 anos da Ditadura Militar: capítulos sobre o ensino de História no Brasil. Curitiba: W\&A Editores, 2014. p. 83-105.

CARDOSO, Oldimar. Para uma definição de didática da História. Revista Brasileira de História, São Paulo, v. 28, n. 55, p. 153-170, 2008.

CARDOSO, Vanessa Clemente. A polêmica História Nova do Brasil: um projeto de vanguarda derrotado politicamente. História \& Ensino, Londrina, v. 22, n. 1, p. 127-154, jan./jun. 2016.

CODATO, Adriano Nervo; OLIVEIRA, Marcus Roberto de. A marcha, o terço e o livro: catolicismo conservador e ação política na conjuntura do golpe de 1964. Revista Brasileira de História, São Paulo, v. 24, n. 47, p. 271-302, 2004.

CZAJKA, Rodrigo. Praticando delitos, formando opinião: intelectuais, comunismo e repressão (1958-1968). 2009. 388 f. Tese (Doutorado em Sociologia) - Universidade Estadual de Campinas, Campinas, 2009.

FERREIRA, Marieta de Moraes. A história como ofício: a constituição de um campo disciplinar. Rio de Janeiro: Editora FGV, 2013.

GUIMARÃES, Lucia Maria Paschoal; LEONZO, Nanci. A reforma de base no ensino da história pátria: o projeto da História Nova do Brasil. Revista de História, São Paulo, n. 149, p. 235-251, 2003.

LACOMBE, Américo Jacobina et al. História Nova (Parecer). Revista do Instituto Histórico e Geográfico Brasileiro, Rio de Janeiro, v. 263, p. 283302, abr./jun. 1964.

LOURENÇO, Elaine. História Nova do Brasil: revisitando uma obra polêmica. Revista Brasileira de História, São Paulo, v. 28, n. 56, p. 385-406, 2008.

MENDONÇA, Sueli Guadelupe de Lima. A experiência da História Nova: uma tentativa de revisão crítica do ensino de História no Brasil nos anos 60. 1990. 69 f. Dissertação (Mestrado em Educação) - Universidade Federal de São Carlos, São Carlos, 1990. 
MENDONÇA, Sueli Guadelupe de Lima. Werneck Sodré, História Nova: contribuição pioneira ao ensino de História no Brasil. In: CUNHA, Paulo; CABRAL, Fátima (org.). Nelson Werneck Sodré: entre o sabre e a pena. São Paulo: Editora Unesp, 2006. p. 327-342.

NORA, Pierre. Entre memória e história: a problemática dos lugares. Projeto História, São Paulo, v. 10, p. 7-29, dez. 1993.

PEREIRA, Daniel Mesquita. Boletim de História: uma experiência de vanguarda na Faculdade Nacional de Filosofia - 1958/1963. 1998. 114 f. Dissertação (Mestrado em História) - Pontifícia Universidade Católica do Rio de Janeiro, Rio de Janeiro, 1998.

PINTO, João Alberto da Costa. A origem e o sentido político do projeto História Nova do Brasil (1963-1965). In: CUNHA, Paulo; CABRAL, Fátima (org.). Nelson Werneck Sodré: entre o sabre e a pena. São Paulo: Editora Unesp, 2006. p. 343-357.

RÜSEN, Jörn; JAEGGER, Friedrich. A cultura da memoração na história da República Federal da Alemanha. In: RÜSEN, Jörn (org.). Cultura faz sentido: orientações entre o ontem e o amanhã. Petrópolis: Vozes, 2014. p. 89-146. SANTOS, Joel Rufino dos et al. História Nova do Brasil. São Paulo: Brasiliense, 1965. v. 1.

SANTOS, Joel Rufino dos et al. História Nova do Brasil: 1963-1993. São Paulo: Loyola: Giordano, 1993.

SODRÉ, Nelson Werneck. História da História Nova. Petrópolis: Vozes, 1987. TOLEDO, Caio Navarro de. ISEB: fábrica de ideologias. São Paulo: Ática, 1977. 